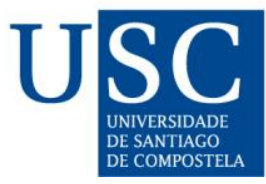

NOva ACTa Científica COMpostelana

BIOLOXÍA

Nova Acta Científica Compostelana, 28, 2021. ISSN: 2340-0021

Artículos científicos

\title{
As coleccións de briozoos do Museo de Historia Natural da USC
}

\section{The Bryozoan collections of the Museum of Natural History of the USC}

\author{
OSCAR REVERTER-GiL ${ }^{1, a}$, JAVIER SOUtO ${ }^{2, b}$ \\ ${ }^{1}$ Museo de Historia Natural da Universidade de Santiago de Compostela, Parque Vista Alegre s/n, 15705 Santiago de Compostela, \\ Spain \\ ${ }^{2}$ Institut für Paläontologie, Fakultät für Geowissenschaften, Geographie und Astronomie, Geozentrum, Universität Wien, \\ Althanstrasse 14, 1090, Wien, Austria \\ a $\underline{\text { oscar.reverter@usc.es, bjavier.souto-derungs@univie.ac.at }}$
}

Recibido: 04/05/2021; Aceptado: 09/08/2021

\section{Resumo}

Abórdase o estudo do material de briozoos conservado no Museo de Historia Natural da Universidade de Santiago de Compostela. O Museo alberga catro coleccións diferentes que conteñen mostras de briozoos: A colección da "Estación de Bioloxía Mariña de Santander", a da "Fauna Mariña de Galicia", a de Tipos, e a Colección Xeral de briozoos, que é con diferenza a máis extensa. En total, estas coleccións conteñen 1065 mostras de briozoos, conservadas en seco, en alcohol ou incluso en formol, correspondentes a 241 especies. Unha pequena parte está exposta ao público, mentres que a meirande parte está depositada na sala de coleccións do Museo. 0 98\% das mostras proceden de augas ibéricas, e máis en concreto o 92\% proceden de Galicia ou de Portugal. 0 84\% do material foi citado en diversas publicacións científicas e un 13\% das mostras foron ademais figuradas, polo que as coleccións constitúen un importante material de referencia. Unha cuarta parte das mostras teñen ademais especial relevancia por distintos motivos: As coleccións albergan catro holotipos e dez paratipos de seis especies; ademais, outras 59 especies son en xeral pouco frecuentes, ou ben o seu material é o único material ibérico ou español que se conserva.

Palabras clave: Colecciones históricas; Biogeografía; Biodiversidad; Península Ibérica; Galicia; Portugal.

\section{Abstract}

The study of the Bryozoan material preserved in the Museum of Natural History of the University of Santiago de Compostela is addressed. The Museum houses four different collections that contain Bryozoan samples: The collection of the "Santander Marine Biology Station", the "Marine Fauna of Galicia", the Types Collection, and the General Collection of Bryozoa, which is by far the most extensive. In total, these collections contain 1065 samples of Bryozoa, preserved dry, in alcohol or even formaldehyde, corresponding to 241 species. A small part is exposed to the public, while most is deposited in the Museum's collection room. The $98 \%$ of the samples come from Iberian waters, and more specifically $92 \%$ come from Galicia or Portugal. The $84 \%$ of the material has been cited in various scientific publications and the 13\% has also been figured, making the collection an important reference material. A quarter of the samples are also particularly relevant for different reasons: The collections house four holotypes and ten paratypes of

Copyright (C) Universidade de Santiago de Compostela. This is an open access article distributed under the terms of the Creative Commons Attribution-NonComercial-NoDerivatives 4.0 International (CC BY-NC-ND 4.0) License. 
six species; in addition, another 59 species are generally uncommon, or their material is the only Iberian or Spanish material currently preserved.

Keywords: Historical Collections; Biogeography; Biodiversity; Iberian Peninsula; Galicia; Portugal.

Título resumido: As coleccións de briozoos do MHNUSC

\section{INTRODUCIÓN}

O Museo de Historia Natural "Luis Iglesias" da Universidade de Santiago de Compostela (MHNUSC) é probablemente o conxunto de patrimonio histórico-científico máis importante de Galicia. Dende 2014 está situado no seu propio edificio, de nova construción, situado no parque Vista Alegre, nunha contorna onde xa hai outros centros culturais e científicos dependentes da Xunta de Galicia ou da Universidade de Santiago de Compostela (USC) (Fig. 1).

Figura 1. O Museo de Historia Natural da USC no Parque de Vista Alegre, Santiago de Compostela: Entrada principal (esquerda) e vista do interior (dereita)
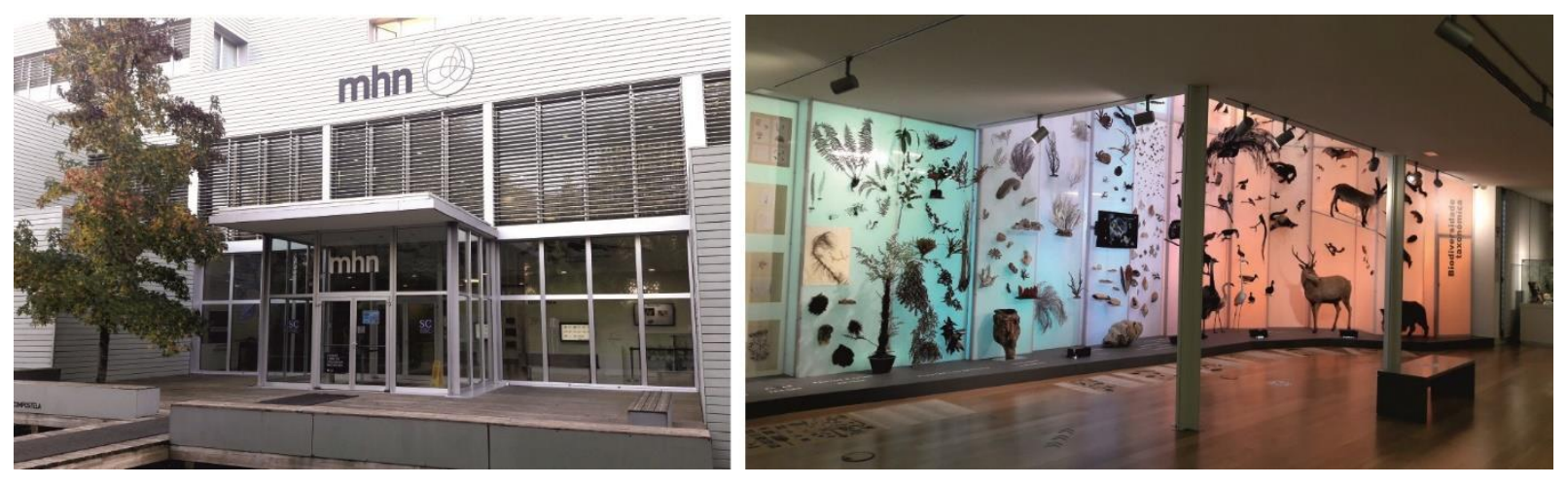

A historia do museo e das coleccións que alberga é longa e complexa, demasiado extensa como para discutila aquí. Por este motivo referímonos ao excelente traballo publicado por BuGALLO RoDRíGUEz (2003) onde se analizan polo miúdo todas as súas vicisitudes históricas e os seus protagonistas. A modo de resumo podemos indicar que, aínda que as orixes do museo poden remontarse ata finais do século XVIII, o Gabinete de Historia Natural, precursor do actual Museo de Historia Natural, orixinouse a mediados do século XIX, cando en 1840 se creou a Cátedra de Historia Natural, cun gabinete asociado cuxo obxectivo principal era a ensinanza práctica. 0 seu primeiro director, Antonio Casares Rodríguez, foi o que comezou o desenvolvemento deste gabinete ata o final da súa vida académica, en 1880. A partir de entón, sucedéronse varias décadas dunha certa decadencia da institución. A principios do século XX, o Gabinete adquiriu o novo nome de Museo de Historia Natural e sitúase no antigo edificio da Universidade. A incorporación daquela do profesor Luis Iglesias ao novo museo, do que foi director durante 45 anos, foi clave para a supervivencia desta institución. Ao final deste período, as coleccións do museo trasladáronse á planta baixa da Facultade de Química. Trala xubilación de Luis Iglesias, en 1965, a Universidade acordou dar o seu nome ao Museo de Historia Natural. Durante a última parte do século XX e 
especialmente nestes primeiros anos do século XXI, a institución continuou gañando importantes coleccións, froito do traballo nos departamentos universitarios e tamén de doazóns privadas. Finalmente, entre 2009 e 2011 acometeuse por primeira vez a construción dun edificio exclusivo para albergar as coleccións do museo, o que dá unha idea da súa maior proxección e importancia social, aínda que debido a múltiples dificultades a nova localización non puido inaugurarse ata outubro de 2014.

Os museos de historia natural teñen dúas funcións diferentes pero complementarias. A máis evidente para o gran público é a función que poderiamos denominar "didáctica", xa que nas salas dos museos hai exemplos de diferentes seres vivos ou minerais, así como representacións de espazos naturais ou da historia evolutiva da vida e as súas complexas relacións. Deste xeito cumpren un papel social e educativo fundamental. Non obstante, os museos xeralmente só mostran unha pequena parte das coleccións que posúen, xa que a maioría delas están gardadas fóra da vista do público. Moitos destes fondos alimentan a segunda función dos museos, que é a que poderiamos chamar "científica" ou "investigadora". En primeiro lugar, hai que ter en conta que cando un investigador describe unha especie nova para a ciencia, debe facelo seguindo uns parámetros estritos establecidos polos Códigos de Nomenclatura. Entre eles está a obriga de designar un exemplar ou exemplares "tipo", que son os que presentan claramente todas as características que permiten diferenciar esta nova especie das outras. Estes exemplares deben depositarse nunha colección de acceso público, para que calquera investigador poida revisar e estudar ese material. Polo xeral estes "tipos" se depositan en museos de historia natural. Pero ademais, moitos investigadores depositan nos museos o material que serviu de base para o seu traballo, ás veces froito do seu esforzo coleccionista privado, noutras procedentes de diferentes campañas de mostraxe. A conservación deste material tamén é moi importante, especialmente cando foi citado ou presentado en publicacións científicas, xa que permite aos futuros investigadores estudalo. Moitos traballos de investigación actuais baséanse en grande medida na revisión de coleccións históricas á luz de novos coñecementos e técnicas. De aí a grande importancia, dende o punto de vista da investigación, da conservación de todo este material.

O filo briozoos ou ectoproctos (véxase REVERTER-GIL et al., 2016) inclúe invertebrados triblásticos celomados, non segmentados e coloniais, que viven fundamentalmente no mar, aínda que tamén habitan en augas salobres e doces. As súas colonias están integradas por un número moi variable de pequenos individuos, chamados zooides, de entre 0,30 e 1,00 mm de lonxitude, que poden ser iguais ou diferentes. Cada zooide pode considerarse integrado por dúas subunidades: un polípido, constituído por unha coroa tentacular ciliada, o tubo dixestivo e o centro nervioso; e un cístido, que rodea ao polípido e contén a cavidade xeral. A coroa tentacular pode retraerse completamente no interior do cístido ou proxectarse ao exterior para capturar o alimento mediante a filtración da auga que o rodea. Os briozoos carecen de aparato excretor, e os produtos de refugallo vanse acumulando nas células do mesodermo e do tracto dixestivo, polo que o polípido acaba por dexenerar, e é substituído por un novo, formado a expensas do cístido, o que constitúe unha característica peculiar deste filo. Os briozoos mariños están presentes en todos os mares do mundo, dende a zona intermareal ata as profundidades abisais. A práctica totalidade das especies son sésiles, é dicir, viven fixas a un substrato que pode ser de natureza moi variada, como algas, pedras, conchas de Moluscos ou incluso substratos artificiais. 
Os briozoos son moito máis abundantes do que poda supoñer un observador non experimentado, debido a que as súas colonias son, en xeral, pequenas e pouco chamativas; por iso, e a pesar da súa abundancia, só unhas poucas especies poden identificarse a simple vista. $\mathrm{Na}$ actualidade coñécense entre 6.000 e 8.000 especies viventes segundo estimacións de distintos autores (véxase por exemplo GoRDON et al., 2009), mentres que se estima que o número total de especies existente situaríase entre 8.700 e 11.100 (APPELTANS et al., 2012). En augas europeas coñécense 945 especies indíxenas (GORDON et al., 2019), mentres que o catálogo de especies ibéricas é dunhas 540 (aproximadamente 420 na fachada atlántica e 340 na mediterránea) (REVERTER-GIL et al., 2014; BOE, 2020 e datos propios inéditos). En Galicia atopáronse ata agora 280 especies (REVERTER-GIL \& SouTO, 2017 e datos propios inéditos).

O MHNUSC conta actualmente cunha pequena pero importante colección (dentro do ámbito ibérico) de exemplares de briozoos. 0 propósito do presente traballo é revisar todo este material, elaborar un catálogo actualizado e dalo a coñecer á comunidade científica.

\section{MATERIAL E MÉTODOS}

Para a realización do presente traballo revisáronse todas as mostras de briozoos depositadas no MHNUSC, localizáronse cales foron citadas ou figuradas en publicacións e renováronse as etiquetas.

Pero, en primeiro lugar, por qué falamos de "coleccións" de briozoos, en plural, e non de "colección"? O material de briozoos depositado no MHNUSC, como o resto de mostras do museo, foise adquirindo ao longo dos anos dende diferentes orixes e en diversas condicións. As mostras de briozoos non constitúen en realidade un conxunto unitario senón que podemos dividilas en catro coleccións ben diferenciadas, tanto pola súa orixe como polo seu contido e importancia:

\section{A Colección da "Estación de Bioloxía Mariña de Santander"}

Segundo relata BugALLo RodRíGuEz (2003), os primeiros briozoos do MHNUSC chegaron a Santiago xunto coa colección de invertebrados mariños que se encargou, en 1911, á Estación de Bioloxía Mariña de Santander, o primeiro centro de estudos mariños fundado en España, en 1886. Entre os obxectivos desta institución figuraba o de preparar coleccións con destino aos museos e establecementos de ensino (SÁNCHEZ Ron, 2020). Remitíronse a Santiago máis de 250 especies, das cales 20 correspondían a briozoos, cada unha nun frasco de vidro e conservada en alcohol. Delas sobreviven na actualidade só 12 mostras de briozoos. Todas elas parecen ter sido recollidas na zona de Santander e case con certeza foron identificados orixinalmente polo briozoólogo español Manuel Gerónimo Barroso (1887-1962), que foi o primeiro investigador español en estudar os briozoos. Este profesor realizou varias estadías na Estación de Bioloxía Marítima de Santander entre 1906 e 1912, recibindo bolsas da "Junta para la Ampliación de Estudios e Investigaciones Científicas" (JAE) e do "Museo Nacional de Ciencias Naturales". Foi durante estas estadías cando iniciou os seus estudos sobre briozoos. 0 seu primeiro artigo, "Briozoos de la estación de biología marítima de Santander", publicado en 1912 na revista "Trabajos del Museo de Ciencias Naturales", foi o primeiro estudo sobre briozoos publicado por un investigador español. Esta monografía presenta información sobre tres especies de entoproctos e case cen ectoproctos, recollidos na súa 
maior parte na costa de Santander, aínda que tamén inclúe algunhas mostras do sur da península. Todas as especies de briozoos que se remitiron orixinalmente dende Santander ao MHNUSC están citadas na monografía de BARroso (1912). Polo tanto, é moi probable que todo o material fose identificado orixinalmente por Barroso e citado na súa monografía de Santander.

A colección de briozoos de Santander, xunto coas demais mostras desta orixe, conta con números de rexistro correlativos no catálogo xeral do MHNUSC e encóntrase en parte exposta ao público na área de invertebrados mariños (Fig. 2), mentres que varias mostras están depositadas na sala de coleccións.

Figura 2. Parte da Colección da “Estación de Bioloxía Mariña de Santander” exposta ao público. O material de briozoos retirouse para o seu estudo

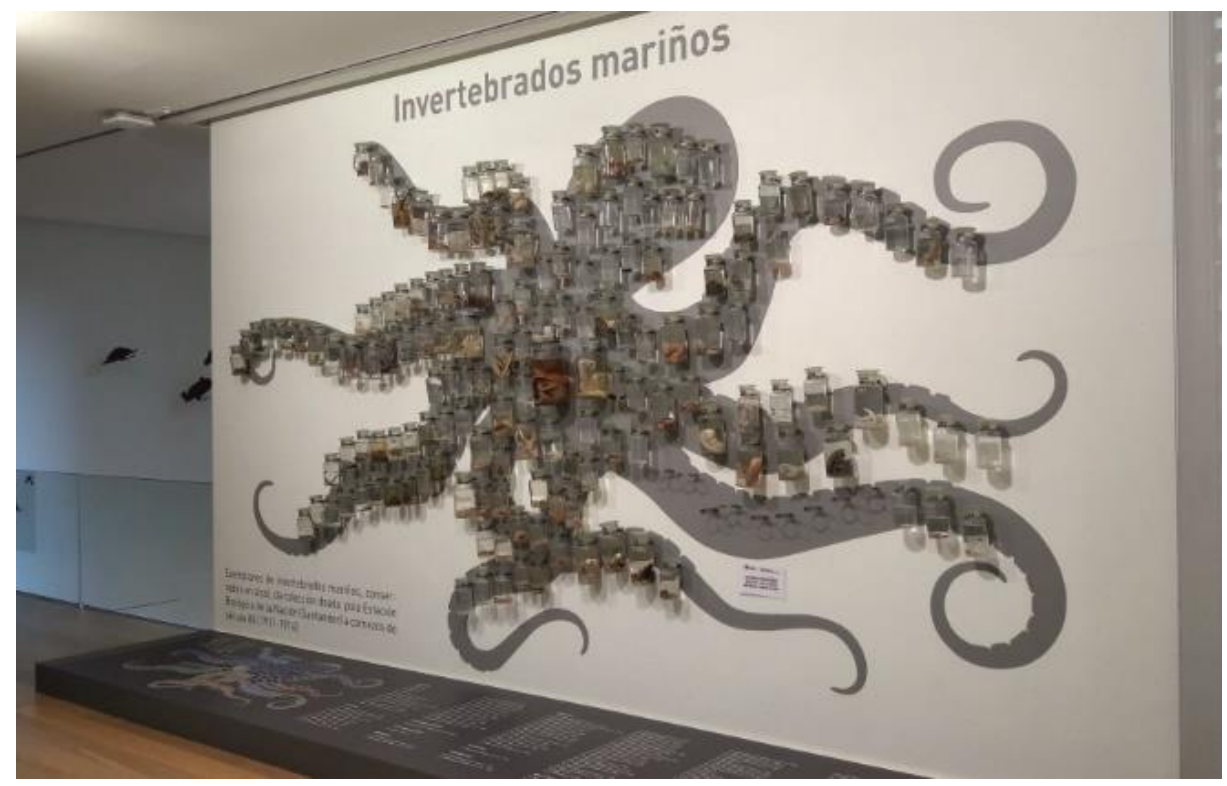

\section{A Colección da "Fauna Mariña de Galicia"}

Segundo Bugallo Rodríguez (2003), durante os anos 80 do pasado século se recolleron, baixo a dirección de Victoriano Urgorri, mostras de fauna mariña en diferentes puntos de Galicia para depositalas no Museo. En conxunto esta colección contén 224 especies de invertebrados mariños, conservadas en alcohol. Nesta colección se inclúen só 10 mostras de briozoos procedentes de distintas localidades galegas.

Como no caso anterior, a colección completa conta con números de rexistro correlativos no catálogo xeral do MHNUSC e encóntrase en parte exposta ao público na área de invertebrados mariños (Fig. 3), mentres que outras mostras están depositadas na sala de coleccións. 
Figura 3. Parte da Colección da "Fauna Mariña de Galicia" exposta ao público, incluíndo unha gran colonia de Pentapora foliacea (arriba á dereita)

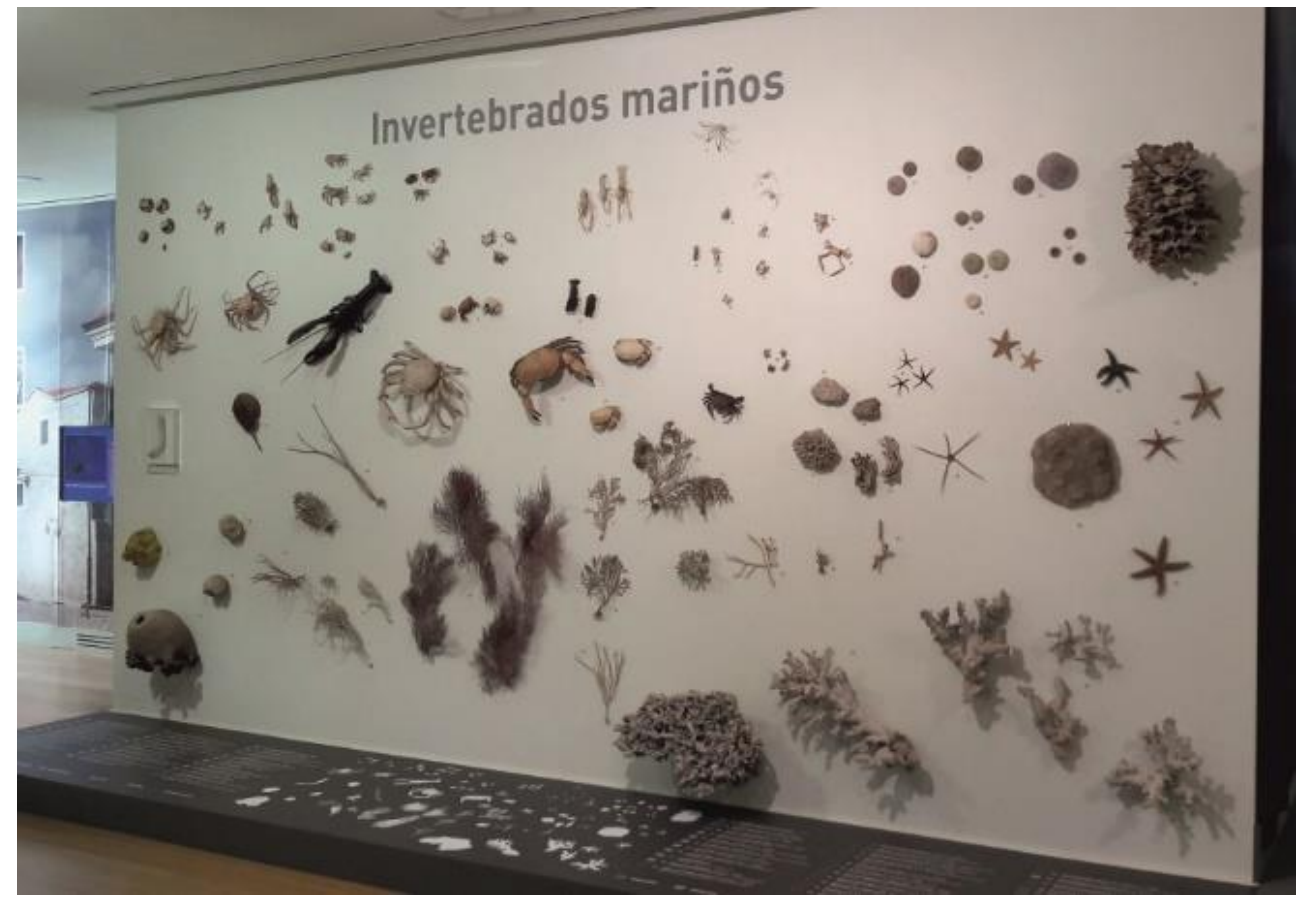

\section{A Colección Xeral de briozoos}

A maior parte, con diferencia, das mostras de briozoos de MHNUSC constitúena a Colección Xeral que os autores doamos ao Museo o 26 de xuño de 2018. Esta colección está composta por 696 lotes que conteñen máis de 1000 mostras, que están identificadas cunha numeración propia, independente do catálogo xeral do museo. Toda a colección está depositada na sala de coleccións, parte conservada en seco, en alcohol ou incluso en formaldehído (Fig. 4). Esta colección foi iniciada a finais dos anos 70 do pasado século por Eugenio Fernández Pulpeiro, o primeiro investigador adicado ao estudo sistemático dos briozoos de Galicia. Durante anos estivo conservando os mellores exemplares recollidos nas nosas augas, especialmente aqueles que constituían novas citas para as nosas costas ou que aparecían figurados nas súas publicacións. Esta pequena colección sufriu un accidente a principios dos anos 90 do século pasado, cando o armario que a albergaba cedeu debido ao peso acumulado (e á súa mala calidade). A pesar de que se puido recuperar unha gran parte das mostras intactas, algúns exemplares, incluso algúns figurados en publicacións, perdéronse irremediablemente. Durante os anos seguintes e ata o presente, grazas a recollidas feitas tanto por Fernández Pulpeiro coma por nós mesmos, sumando incluso o material doado para o seu estudio por outros investigadores e algúns particulares, a colección foi aumentando con exemplares procedentes principalmente de Galicia e Portugal, pero tamén doutras orixes diversas. Boa parte deste material citouse en varias publicacións e parte del foi figurado, polo que constitúe un material de referencia de importancia no ámbito ibérico. 
Figura 4. A Colección Xeral de briozoos na sala de coleccións do MHNUSC

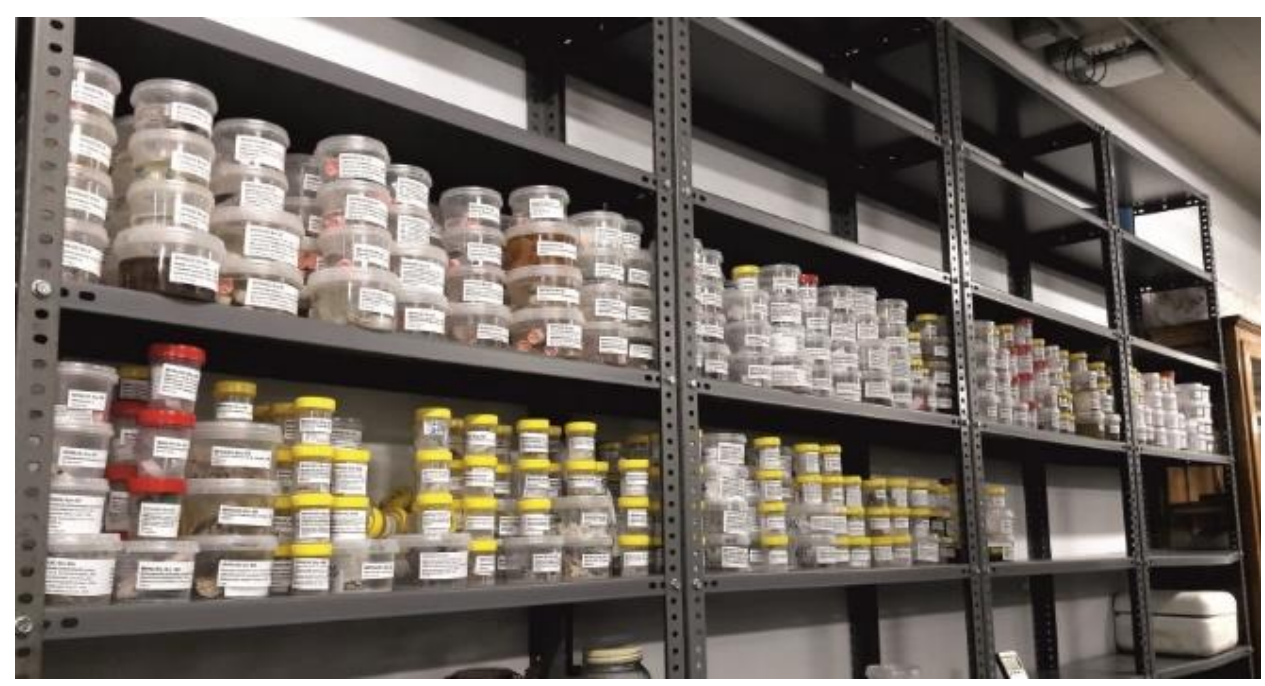

\section{A Colección de material Tipo}

Como comentamos anteriormente, todas as novas especies descritas deben ter exemplares que sirvan como modelo, os chamados "exemplares tipo". Todos os que existen nas coleccións do MHNUSC consérvanse nunha tipoteca única, que se atopa dentro da sala de coleccións (Fig. 5). Polo momento contén poucos exemplares de briozoos, con catro holotipos e dez paratipos correspondentes a seis especies. Isto non se debe a que se describiran poucas especies en augas galegas, onde levamos a cabo gran parte do noso traballo de investigación, senón porque durante anos os tipos das novas especies de briozoos de Galicia foron depositados nos museos de historia natural de Londres (NHMUK) e de París (MNHN). 0 de Londres alberga seguramente a mellor colección de briozoos do mundo. 0 de París conserva a mellor colección de briozoos de augas ibéricas profundas. En épocas posteriores os exemplares tipo foron depositados no "Museo Nacional de Ciencias Naturales" de Madrid (MNCN), porque os proxectos de investigación cos que se obtivo o material foron financiados polo Ministerio e parecía máis apropiado depositar alí tanto o material tipo como outro material recollido. Outros tipos de especies galegas foron depositados no "Oberösterreichisches Landesmuseum" (OLL) de Linz (Austria) e no "Senckenberg Forschungsinstitut und Naturmuseum" (SFM) de Frankfurt (Alemaña) debido a que o material galego fora recolectado por campañas organizadas dende distintas institucions internacionais. Recentemente comezamos a depositar o noso material tipo no MHNUSC como resultado da transferencia da nosa colección xeral. 
Figura 5. Material tipo de briozoos na Colección de Tipos do MHNUSC

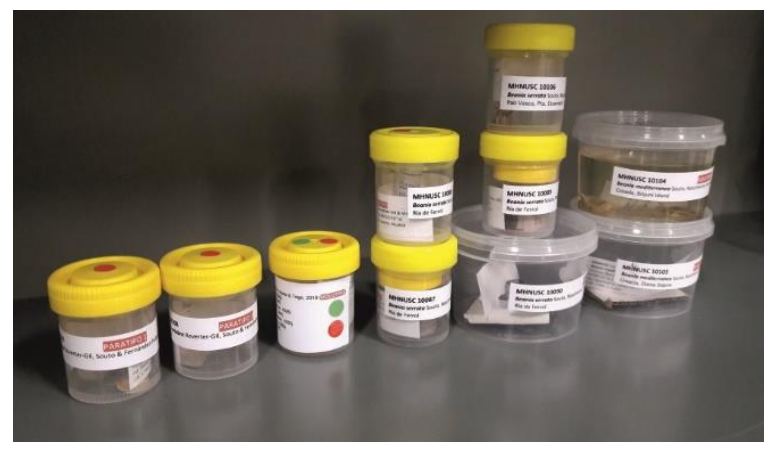

Por último, na sala de coleccións do Museo se encontran almacenadas tamén varias caixas que conteñen material de briozoos procedente de campañas de mostraxe realizadas no canal de Menorca (Baleares), nas illas Berlengas (Portugal) e na Arrábida (Portugal), así como restos dun oso de balea. Este material está aínda pendente de estudar e identificar.

\section{RESULTADOS}

\section{A Colección da "Estación de Bioloxía Mariña de Santander"}

Como xa se mencionou anteriormente, das 20 mostras de briozoos enviadas desde Santander a principios do século pasado ao MHNUSC, só se conservan actualmente 12 mostras, que conteñen 14 especies en total.

Aínda que estas especies son relativamente frecuentes na costa ibérica, o feito de formar parte do material de referencia da obra de BARRoso (1912) confire a esta pequena colección unha certa relevancia. 0 resto do material que este autor publicou na súa monografía atópase actualmente depositado no Museo Marítimo Cantábrico (MMC) e no Museo Nacional de Ciencias Naturais (MNCN), e foi revisado por Álvarez (1991). Polo tanto, os datos que se aportan aquí completan a revisión feita por este autor.

MHNUSC 6941: Crisia denticulata (Lamarck, 1816): A mostra inclúe unha etiqueta manuscrita que indica "Crisia denticulata, B 1911, Santander", polo que parece claro que este material foi identificado orixinalmente por Barroso nese ano e que corresponde ao citado por BARROSO (1912). Esta mostra está exposta ao público, conservada en alcohol. No MMC consérvase outra mostra orixinal desta especie citada por este autor (véxase ÁlvAREZ, 1991).

MHNUSC 6942: Mimosella gracilis Hincks, 1851: Colonias sobre algas, conservadas en formol, recollidas na Bahía de Santander e citadas por BARRoso (1912). No MMC consérvase outra mostra orixinal desta especie (véxase ÁlvAREZ, 1991). A mostra está na sala de coleccións.

MHNUSC 6943: Savignyella lafontii (Audouin, 1826): Corresponde a material citado como Eucratea lafontii por BARRoso (1912), recollido na Bahía de Santander ou en Las Machinas. No MMC 
e no MNCN consérvanse outras dúas mostras desta especie citadas por este autor (véxase ÁLVAREZ, 1991). A mostra contén ademais outras especies de briozoos como Scruparia chelata (Linnaeus, 1758), Bugula neritina (Linnaeus, 1758) e Chartella papyracea (Ellis \& Solander, 1786). Esta mostra está exposta ao público, conservada en alcohol.

MHNUSC 6944: Scruparia chelata (Linnaeus, 1758): varias colonias sobre algas recollidas en Santander e citadas por BARRoso (1912, como Eucratea chelata). Esta mostra está exposta ao público, conservada en alcohol. Contén ademais colonias de Crisularia plumosa (Pallas, 1766). No MMC consérvanse outras dúas mostras orixinais de $S$. chelata (véxase ÁlvarEz, 1991).

MHNUSC 6945: Cradoscrupocellaria ellisi (Vieira \& Spencer Jones, 2012): A mostra inclúe unha etiqueta manuscrita que indica "Scrupocellaria reptans Linneo, Barroso 1910". BARRoso (1912) indica que se recolleron colonias de $S$. reptans sobre zosteras na Bahía de Santander e sobre algas en Peña Vieja, así como sobre un crustáceo. Dado que o presente material crece sobre algas, probablemente proceda de Peña Vieja. De todos xeitos, en BARRoso (1912) tamén se cita material de Cádiz, polo que non podemos estar absolutamente seguros da procedencia do noso material. Segundo Álvarez (1991) no MMC e no MNCN consérvanse varias mostras de BARRoso (1912) etiquetadas como $S$ reptans, das que na súa opinión algunha podería corresponder a Scrupocellaria bertholleti (Audouin, 1826). Non obstante, todo este material debe ser revisado seguindo os recentes traballos de VIEIRA \& SPENCER JONES (2012) e VIEIRA et al. (2013), onde se redescriben varias especies e se describen outras novas, tanto do xénero Scrupocellaria como de Cradoscrupocellaria. A mostra, que está exposta ao público e conservada en alcohol, contén tamén colonias de $S$. chelata.

MHNUSC 6946: Bicellariella ciliata (Linnaeus, 1758): Corresponde a material citado como Bicellaria ciliata por BARRoso (1912) recollido na costa de Santander. Contén tamén anacos de Chartella papyracea (Ellis \& Solander, 1786). Esta mostra está exposta ao público, conservada en alcohol. No MMC consérvase outra mostra orixinal desta especie (véxase ÁlvAREZ, 1991).

MHNUSC 6947: Bugula neritina (Linnaeus, 1758): Colonias soltas, recollidas en Las Machinas (Santander) e citadas por BARRoso (1912). Contén tamén colonias de S. lafontii. Esta mostra está exposta ao público, conservada en alcohol. No MMC consérvanse outras dúas mostras orixinais de B. neritina (véxase ÁLVAREZ, 1991), así como outra máis no MNCN.

MHNUSC 6948: Membranipora membranacea (Linnaeus, 1767): Probablemente corresponda ao material citado por BARRoso (1912) da Bahía de Santander ou da Magdalena. Esta mostra está exposta ao público, conservada en alcohol. No MMC consérvase outra mostra desta especie citada por este autor (véxase ÁLVAREZ, 1991).

MHNUSC 6949: Electra pilosa (Linnaeus, 1767): Probablemente corresponda ao material citado por BARRoso (1912) da área de Santander. No MMC consérvanse outras mostras desta especie citadas por este autor (véxase ÁlvAREZ, 1991). Esta mostra está exposta ao público, conservada en alcohol.

MHNUSC 6950: Pentapora foliacea (Ellis \& Solander, 1786): BARRoso (1912, como Lepralia foliacea) indica que se recolleron colonias desta especie mediante palangre en diferentes localidades de Santander. Esta mostra está exposta ao público, conservada en alcohol. No MMC consérvase outra mostra orixinal desta especie (véxase ÁlvAREZ, 1991). 
MHNUSC 6951: Porella compressa (J. Sowerby, 1805): A mostra inclúe unha etiqueta manuscrita que indica "Porella compressa Sowerby, Barroso 1911", polo que é evidente que este material foi identificado orixinalmente por Barroso nese ano e é parte do citado en BARRoso (1912) recollido mediante palangre en diferentes localidades. Esta mostra está exposta ao público, conservada en alcohol. No MMC consérvanse outras dúas mostras orixinais (véxase ÁlVAREZ, 1991).

MHNUSC 6952: Turbicellepora magnicostata (Barroso, 1919): A mostra inclúe unha etiqueta manuscrita que di "Cellepora avicularis Hincks, B 1911", o que indica que este material foi identificado orixinalmente por Barroso nese ano. Probablemente corresponda a material citado como Cellepora avicularis Hincks por BARRoso (1912) procedente da área da Bahía de Santander, aínda que no mesmo traballo se cita a especie tamén de Alxeciras. Esta mostra encóntrase exposta ao público, conservada en alcohol. No MMC consérvanse dúas mostras de BARRoso (1912 como Cellepora avicularis), que tamén corresponden a T. magnicostata (véxase ÁlvAREZ, 1991).

Outras especies que foron remitidas orixinalmente dende a Estación de Bioloxía Mariña de Santander, pero que se perderon son:

Flustrella hispida (Fabricius, 1780): BARRoso (1912) cita colonias sobre Fucus na Magdalena. No MMC consérvase unha mostra co mesmo nome, que segundo Álvarez (1991) corresponde efectivamente a Flustrellidra hispida (Fabricius, 1780).

Bowerbankia pustulosa (Ellis \& Solander, 1786): BARROSO (1912) citou exemplares recollidos en San Vicente de la Barquera. ÁLVAREz (1991) non encontrou este material nin no MMC nin no MNCN, polo que é posible que a única mostra existente fora a remitida a Santiago e agora lamentablemente perdida. Non é posible saber a qué especie correspondería realmente, xa que esta especie é frecuentemente confundida con outras similares.

Bugula plumosa (Pallas, 1766): BARRoso (1912) cita numerosas colonias procedentes da Bahía de Santander. Dúas mostras desta especie consérvanse no MMC e unha no MNCN (ÁlvAREZ, 1991). Aínda que a mostra remitida a Santiago perdeuse, na mostra MHNUSC 6944 (Scruparia chelata) atopamos material de Crisularia plumosa (denominación actual da especie).

Flustra papyracea Ellis \& Solander, 1786: BARRoso (1912) citou esta especie en numerosas localidades, e dúas mostras consérvanse aínda no MMC (ÁLVAREZ, 1991). En dúas mostras da colección (MHNUSC 6943: Savignyella lafontii e MHNUSC 6946: Bicellariella ciliata) atopamos anacos e colonias de Chartella papyracea (denominación actual da especie).

Electra pilosa var. verticillata (Ellis \& Solander, 1786): BARRoso (1912) citou esta especie en Peña Vieja, e aínda consérvanse dúas mostras no MMC que segundo ÁlvarEz (1991) corresponden efectivamente a E. verticillata.

Cellaria fistulosa (Linnaeus, 1758): BARroso (1912) citou numerosas colonias na Bahía, e unha mostra aínda consérvase no MMC (ÁLVAREZ, 1991).

Smittia cervicornis (Pallas, 1766): BARroso (1912) citou a especie de diversas localidades. A única mostra que se conserva no MMC corresponde efectivamente a Smittina cervicornis segundo ÁlvarEz (1991). 
Retepora beaniana King, 1846: BARRoso (1912) cita anacos desta especie de El Charco. As dúas mostras que se conservan no MMC corresponden efectivamente a Reteporella beaniana segundo ÁLVAREZ (1991 como Sertella beaniana).

\section{A Colección da Fauna Mariña de Galicia}

Esta colección, recollida en augas galegas, só inclúe 10 mostras de briozoos que conteñen 11 especies en total. Ningunha delas parece ter sido citada nunha publicación.

MHNUSC 6640: Electra pilosa (Linnaeus, 1767): varias colonias sobre algas recollidas en Segaño, ría de Ferrol, en 1985. Mostra conservada en alcohol na sala de coleccións.

MHNUSC 6641: Electra verticillata (Ellis \& Solander, 1786): Varias colonias recollidas en Ponteceso, ría de Corme e Laxe, en 1983. Contén tamén colonias de E. pilosa. Mostra conservada en alcohol na sala de coleccións.

MHNUSC 6642: Membranipora membranacea (Linnaeus, 1767): colonias sobre Laminaria sp., recollidas en Segaño, ría de Ferrol, en 1985. Mostra conservada en alcohol na sala de coleccións.

MHNUSC 6643: Chartella papyracea (Ellis \& Solander, 1786): varias colonias recollidas a $9 \mathrm{~m}$ de profundidade no teito dunha cova en Batel, ría de Ferrol, en 1985. Inclúe tamén colonias de Scrupocellaria scruposa (Linnaeus, 1758). Mostra conservada en alcohol na sala de coleccións.

MHNUSC 6644: Bugula neritina (Linnaeus, 1758): Numerosas colonias oviceladas, descoloridas, recollidas a $3 \mathrm{~m}$ de profundidade no peirao de A Cabana, ría de Ferrol, en 1985. Mostra conservada en alcohol na sala de coleccións.

MHNUSC 6645: Turbicellepora magnicostata (Barroso, 1919): Unha gran colonia sobre pedra, recollida en Cariño, ría de Ferrol, en 1986. Contén tamén colonias de Haplopoma graniferum (Johnston, 1847). Mostra conservada en alcohol na sala de coleccións.

MHNUSC 6646: Pentapora foliacea (Ellis \& Solander, 1786): Un anaco de colonia conservado en alcohol, recollido en Leuseda, ría de Ferrol, en 1985. Mostra conservada en alcohol na sala de coleccións.

MHNUSC 6647: Flustrellidra hispida (Fabricius, 1780): colonias recollidas sobre Fucus serratus Linnaeus, 1753 en Mera, ría de A Coruña, en 1975. Mostra conservada en alcohol na sala de coleccións.

MHNUSC 6648: Amathia imbricata (Adams, 1798): Numerosas colonias sobre Fucus sp. recollidas en A Cabana, ría de Ferrol, en 1984. Mostra conservada en alcohol na sala de coleccións.

MHNUSC 6671: Pentapora foliacea (Ellis \& Solander, 1786): Gran exemplar en seco, exposto ao público xunto con outros invertebrados mariños (Fig. 3); probablemente procedente da enseada de Leuseda, ría de Ferrol. 


\section{A Colección Xeral de briozoos}

Como se comentou anteriormente, esta colección alberga, de lonxe, a maior parte das mostras de briozoos do MHNUSC, incluíndo 696 lotes, pero cun total de 1029 mostras. Isto débese a que cada lote á súa vez pode conter máis dunha mostra. Os lotes están numerados co seu propio código, independente do código xeral do museo (MHNUSC-Bry). Cando hai varias mostras nun lote, levan o mesmo número e máis unha letra identificativa (por exemplo, MHNUSC-Bry 150a, MHNUSC-Bry 150b, MHNUSC-Bry 150c ...). Cada mostra pode conter varias especies que comparten o mesmo substrato, como unha cuncha ou unha pedra, así como varias colonias da mesma especie. Preferiuse numerar cada mostra e non cada especie ou colonia, xa que sería demasiado confuso á hora de levar a cabo buscas de especies na base de datos. Esta colección contén 235 especies.

Case todas as mostras (98\%) proceden de augas ibéricas, a maioría de Galicia (78\%) e Portugal (14\%). A lista completa de mostras desta colección, con todos os seus datos, é demasiado extensa para incluíla aquí, pero pódese consultar accedendo ao ficheiro correspondente na propia páxina do MHNUSC: http://www2.usc.es/museohn/coleccions/fauna marina.html.

\section{A Colección de Tipos}

Existen 14 mostras con material de tipo de varias especies de briozoos depositados na tipoteca da sala de coleccións. En total conteñen 13 especies:

MHNUSC 10087: Holotipo de Beania serrata Souto, Nascimento, Reverter-Gil \& Vieira, 2018, recollido na Ría de Ferrol.

MHNUSC 10088, 10089, 10090 y 10106: Paratipos de Beania serrata Souto, Nascimento, Reverter-Gil \& Vieira, 2018, recollidos na Ría de Ferrol e en Punta Etxandarri (País Vasco).

MHNUSC 10091: Holotipo de Schizotheca galaica Reverter-Gil, Souto \& Trigo, 2019: Esta mostra, que consiste en dous pequenos anacos de Porella compressa (J. Sowerby, 1805) recollidos perto de Laxe (Galicia), contén ademais colonias de Chorizopora brongniartii (Audouin, 1826), Copidozoum planum (Hincks, 1880a), Cribrilaria venusta (Canu \& Bassler, 1925), Figularia figularis (Johnston, 1847), Micropora coriacea (Johnston, 1847), Microporella ciliata (Pallas, 1766), así como colonias de Ciclostomados non identificados.

MHNUSC 10104: Holotipo de Beania mediterranea Souto, Nascimento, Reverter-Gil \& Vieira, 2018, recollido en Croacia.

MHNUSC 10105: Paratipo de Beania mediterranea Souto, Nascimento, Reverter-Gil \& Vieira, 2018, recollido en Croacia.

MHNUSC 10107: Paratipo de Metroperiella gay Reverter-Gil, Souto \& Fernández-Pulpeiro, 2009, recollido na ría de Vigo.

MHNUSC 10108: Paratipo de Schizoporella artabra Reverter-Gil, Souto \& Fernández-Pulpeiro, 2009, recollido na ría de Ferrol.

MHNUSC 10120: Holotipo de Setosella margaritae Reverter-Gil \& Souto, 2021, recollido na ría de Ferrol. 
MHNUSC 10121-10123: Paratipos de Setosella margaritae Reverter-Gil \& Souto, 2021, recollidos na ría de Ferrol.

\section{DISCUSIÓN}

A modo de resumo de todo o comentado anteriormente, podemos indicar que as Coleccións de briozoos do MHNUSC conteñen un total de 1065 mostras, das que 1029 se encontran na Colección Xeral, 14 na Colección de Tipos, 12 na de "Santander" e 10 na da "Fauna de Galicia".

En canto ao número de especies, o total é de 241, correspondendo 235 á Colección Xeral, a máis extensa, 14 na de "Santander", 13 especies na Colección de Tipos e 11 na da "Fauna de Galicia". A especie máis común nas coleccións é Microporella ciliata (Pallas, 1766) presente en 72 mostras. Non obstante, hai que ter en conta que esta especie foi redescrita non hai moito por KUKLIŃSKI \& TAYLOR (2008), que designan un neotipo e describen novas especies, e que tamén se describiron novas especies do xénero en diferentes traballos recentes (véxase por exemplo HARMELIN et al., 2011 e RAMALHO \& LÓPEZ-FÉ, 2020). 0 material de $M$. ciliata no MHNUSC debe ser revisado xa que é probable que corresponda en realidade a máis dunha especie, pero ese estudo está fóra dos obxectivos do presente traballo. Outras especies abundantes nas coleccións son: Chorizopora brongniartii (Audouin, 1826) (65 mostras), Terwasipora complanata (Norman, 1864) (43 mostras), Schizomavella (Schizomavella) teresae Reverter-Gil \& Fernández-Pulpeiro, 1996 (41 mostras), Schizoporella dunkeri (Reuss, 1848) (40 mostras), Celleporella hyalina (Linnaeus, 1767) (37 mostras), Scruparia chelata (Linnaeus, 1758) (35 mostras), Schizomavella (Schizomavella) linearis (Hassall, 1841) (34 mostras), Electra pilosa (Linnaeus, 1767) (28 mostras), Fenestrulina malusii (Audouin, 1826) (27 mostras), Watersipora subatra (Ortmann, 1890) (27 mostras), Cribrilaria innominata (Couch, 1844) (26 mostras), Cribrilaria venusta (Canu \& Bassler, 1925) (23 mostras), Schizomavella (Schizomavella) auriculata (Hassall, 1842) (23 mostras), Celleporina hassallii (Johnston, 1847) (22 mostras), Cradoscrupocellaria ellisi (Vieira \& Spencer Jones, 2012) (22 mostras), Rhynchozoon bispinosum (Johnston, 1847) (21 mostras), Schizotheca fissa (Busk, 1856) (21 mostras) e Flustrellidra hispida (Fabricius, 1780) (20 mostras).

Ningunha das mostras da Colección de "Fauna de Galicia" foi citada en publicacións, mentres que todas as pertencentes ás Coleccións de Tipos e de "Santander" foron citadas, así como moitas da Colección Xeral. En total, 869 mostras foron citadas en diversas publicacións científicas, mentres outras 28 apareceron en Teses de Doutoramento e noutros traballos académicos. En resumo, o 84\% do material de briozoos do MHNUSC foi citado en distintos traballos. Por outra banda, ningunha das especies das coleccións de "Santander" e de "Fauna de Galicia" foi figurada, mentres que dez mostras da Colección de tipos e 134 da Colección Xeral foron figuradas en diversos artigos (o 13\% do total de mostras).

Só 18 mostras proceden de fóra da península ibérica, concretamente de Francia, Alemaña, Noruega, Croacia, Brasil e Nova Zelandia. Todas as demais (98\%) proceden de augas ibéricas. Delas, 832 proceden de Galicia (78\%) e 146 de Portugal (14\%). É dicir, o 92\% de todo o material das coleccións de briozoos procede da fachada atlántica ibérica, dende Ribadeo ata o Algarve. Outras mostras ibéricas proceden das Baleares, Santander, Andalucía, Asturias, Cataluña, País Vasco, Valencia, e incluso de Ceuta. De entre o material galego, o máis abundante (281 mostras) 
procede de Vigo (incluíndo as illas Cíes), 190 da ría Ferrol, 121 da Costa da Morte e 95 da ría de Ribadeo. 0 resto de mostras proceden de numerosas localidades ao longo de toda a costa galega.

A maioría das mostras (82\%), foron recollidas orixinalmente por só catro persoas: E. Fernández-Pulpeiro (316 mostras, 34\%), J. Souto (248 mostras, 24\%), 0. Reverter-Gil (144 mostras, 13\%) e J.E. Trigo (114 mostras, 11\%). Outros autores ou particulares que contribuíron significativamente ás colecciones son J.L. Redondo, H. De Blauwe, M. Zabala, M.C. Lorenzo Villar, M.G. Barroso e F. Ramil.

En canto á identificación do material, a maior parte foi identificada por 0. Reverter-Gil (56\% das identificacións), por J. Souto (16\%), e por M.C. Barcia-Leal e E. Fernández-Pulpeiro, cun 11\% cada un. En conxunto, representan o $94 \%$ do total de identificacións. Outros autores con contribucións significativas foron H. De Blauwe, M. Zabala e M.G. Barroso.

Por outra banda, 65 das especies conservadas nas coleccións de briozoos (unha cuarta parte do total), teñen especial relevancia por distintos motivos. En primeiro lugar, aquelas especies cuxo material tipo está depositado no MHNUSC:

Beania mediterranea Souto, Nascimento, Reverter-Gil \& Vieira, 2018. No MHNUSC están depositados o Holotipo e Paratipos.

Beania serrata Souto, Nascimento, Reverter-Gil \& Vieira, 2018. No MHNUSC están depositados o Holotipo, Paratipos e outro material recollido trala descrición da especie. Único material no mundo.

Metroperiella gay Reverter-Gil, Souto \& Fernández-Pulpeiro, 2009. No MHNUSC está depositado un Paratipo. O Holotipo e Paratipos están depositados no MNCN. Hai dúas mostras máis na Colección Xeral que non son da serie tipo. Só hai outra cita da especie, en Cataluña.

Schizoporella artabra Reverter-Gil, Souto \& Fernández-Pulpeiro, 2009. No MHNUSC está depositado un Paratipo. 0 Holotipo e Paratipos están depositados no MNCN. Non se coñecen máis citas da especie.

Schizotheca galaica Reverter-Gil, Souto \& Trigo, 2019. No MHNUSC está depositado o Holotipo e único exemplar existente da especie.

Setosella margaritae Reverter-Gil \& Souto, 2021. No MHNUSC están depositados o Holotipo e Paratipos, que constitúen o único material ibérico da especie.

Outras 59 especies son interesantes por ser exemplares únicos en Galicia, España ou na península ibérica, ou por estar pouco citadas en xeral:

Aetea longicollis Jullien in Jullien \& Calvet, 1903. Moi poucas citas da especie a nivel mundial. No MHNUSC consérvase material procedente de Galicia.

Alcyonidium variegatum Prouho, 1892. Moi poucas citas da especie a nivel mundial. No MHNUSC consérvase material de Ferrol; outra colonia da mesma orixe está depositada no MNHN.

Amathia citrina (Hincks, 1877). Na península ibérica esta especie só se coñece do norte de Portugal e máis de Galicia, que é de onde procede o material do MHNUSC.

Amathia pustulosa (Ellis \& Solander, 1786). Na península ibérica esta especie só se coñece de Bilbao, Santoña así como de Galicia, que é de onde procede o material do MHNUSC. 
Anguinella palmata van Beneden, 1845. Na península ibérica esta especie só foi citada de Portugal, cuxo material se conserva no MHNUSC. É polo tanto o único material ibérico que existe.

Antarctothoa galaica (César-Aldariz, Fernández-Pulpeiro \& Reverter-Gil, 1999). Especie só coñecida en Galicia. 0 material tipo está no NHMUK e no MNHN. No MHNUSC consérvase outro material non tipo.

Arbopercula angulata (Levinsen, 1909). É unha especie que adoita atoparse sobre substratos flotantes arredor do mundo, especialmente en áreas tropicais. En augas ibéricas só parece haberse recollido na área do Estreito de Xibraltar e en Menorca (de onde procede o material conservado no MHNUSC), pero a súa presenza aínda non fora sinalada formalmente ata a data.

Barrosia balearica Souto, Reverter-Gil \& Fernández-Pulpeiro, 2010a. Descrita por nós de Baleares. Non foi citada de novo. 0 material tipo está no MNCN. Hai unha mostra no MHNUSC, remitida por M. Zabala.

Buffonellaria muriella Berning \& Kukliński, 2008. Na península ibérica esta especie só foi citada de Galicia. Este material consérvase no MHNUSC, e é o único material ibérico que existe.

Buskia socialis Hincks, 1887. Na península ibérica esta especie só é coñecida de Aveiro e máis da ría de Vigo, que é de onde procede o material conservado no MHNUSC; é o único material español.

Callopora discreta (Hincks, 1862). Na península ibérica esta especie só foi citada en Galicia. Material desta especie consérvase no MHNUSC. É polo tanto o único material ibérico que existe.

Caulorhamphus spiniferum (Johnston, 1832). Na península ibérica esta especie só foi citada en Galicia. Material desta especie consérvase no MHNUSC. É o único material ibérico que existe.

Celleporina derungsi Souto, Reverter-Gil \& Fernández-Pulpeiro, 2010b. Especie descrita de Portugal. 0 material tipo está no MNCN. No MHNUSC hai máis material de Portugal e material de Galicia, o único español.

Chaperiopsis annulus (Manzoni, 1870). Na península ibérica esta especie foi citada en Galicia e en cabo de Gata. Material galego desta especie consérvase no MHNUSC. É o único material ibérico conservado.

Cheiloporina circumcincta (Neviani, 1896). Moi poucas citas da especie a nivel mundial. No MHNUSC consérvase material de Galicia.

Collarina macaronensis Harmelin in Harmelin et al., 2019. Na península ibérica esta especie só se coñece no País Vasco e máis en Galicia, de onde procede o material conservado no MHNUSC, o único material ibérico conservado.

Cradoscrupocellaria ellisi (Vieira \& Spencer Jones, 2012). Esta especie foi confundida con Scrupocellaria reptans, moi citada nas costas ibéricas. Sen revisar o material orixinal non é posible saber a que especie corresponde realmente cada cita. 0 único material ibérico revisado na actualidade é o conservado no MHNUSC.

Cradoscrupocellaria reptans (Linnaeus, 1758). Parte do material citado en Galicia como Scrupocellaria reptans pertence realmente a esta especie. Polo tanto, este material é o único revisado da especie que existe nas costas ibéricas, aínda que é posible que outras citas feitas como S. reptans sexan tamén correctas. 
Cribrilaria bifida (d'Hondt, 1970). Na península ibérica esta especie só é coñecida no Golfo de Cádiz e máis en Galicia, que é de onde procede o material conservado no MHNUSC. Hai pouco material ibérico conservado.

Dentiporella saldanhai Souto, Reverter-Gil \& Fernández-Pulpeiro, 2010b. Descrita de Portugal. O material tipo está no MNCN. No MHNUSC hai unha colonia de Galicia, o único material español.

Ellisina gautieri Fernández Pulpeiro \& Reverter Gil, 1993. Especie pouco citada a nivel global. No MHNUSC consérvase material de Galicia.

Escharella labiosa (Busk, 1856). Na península ibérica esta especie só foi citada en Galicia. Material desta especie consérvase no MHNUSC, e é o único material ibérico que existe.

Fenestrulina asturiasensis Álvarez, 1992. A especie só foi citada de Asturias (Holotipo depositado no MNCN) e de Galicia (material depositado no MHNUSC).

Fenestrulina barrosoi Álvarez, 1993. A especie só foi citada de Alborán (Holotipo depositado no MNCN) e de Galicia (material depositado no MHNUSC).

Fenestrulina inesae Souto, Reverter-Gil \& Fernández-Pulpeiro, 2010b. Especie descrita de Portugal. 0 seu material tipo está depositado no MNCN. No MHNUSC hai máis material da localidade tipo. Non hai máis citas da especie.

Glabrilaria corbula (Bishop \& Househam, 1987). Na península ibérica esta especie só foi atopada en Galicia. Material desta especie se conserva no MHNUSC, e é o único material ibérico que existe.

Haplopoma sciaphilum Silén \& Harmelin, 1976. Na península ibérica esta especie só é coñecida do Algarve e máis de Galicia, de onde procede o material conservado no MHNUSC, que é o único material español.

Hippoporina teresae Souto, Reverter-Gil \& Fernández-Pulpeiro, 2010b. Especie descrita de Portugal. O seu material tipo está depositado no MNCN. No MHNUSC hai máis material da localidade tipo. Non hai máis citas da especie.

Mollia cristinae Souto, Reverter-Gil \& Fernández-Pulpeiro, 2010b. Especie descrita de Portugal. O seu material tipo está depositado no MNCN. No MHNUSC hai máis material da localidade tipo. Non hai máis citas da especie.

Mollia multijuncta (Waters, 1879). Especie moi pouco citada a nivel global. No MHNUSC consérvase material de Cataluña, enviado por M. Zabala.

Pacificincola perforata (Okada \& Mawatari, 1937). Esta especie, propia do Pacífico noroccidental, foi recentemente introducida en Europa, encontrándose en Bélxica e na Bretaña. Exemplares desta última localidade consérvanse no MHNUSC, así como tamén no NHMUK, no MNHN e no MNCN.

Panolicella nutans Jebram, 1985. Especie moi pouco citada a nivel global. 0 material do MHNUSC é o único ibérico conservado.

Prenantia spectrum (Jullien, 1882). Especie descrita do norte de Portugal (o material tipo consérvase no MNHN) e reencontrada en Galicia, cuxo material consérvase no MHNUSC. É o único material español que existe. 
Puellina directa Bishop \& Househam, 1987. Especie moi pouco citada a nivel global: só no Canal da Mancha e máis en Galicia, que é de onde procede o material conservado no MHNUSC, o único ibérico.

Puellina modica Bishop \& Househam, 1987. Moi poucas citas da especie a nivel mundial: só do Mar de Irlanda, no Canal da Mancha e máis en Galicia, que é de onde procede o material conservado no MHNUSC, o único material ibérico.

Puellina nana Reverter-Gil \& Fernández-Pulpeiro, 2007. Especie descrita de Galicia, moi pouco citada a nivel global: só de Galicia e de Bélxica. O Holotipo está depositado no MNHN. Existe unha pequena mostra máis da ría de Ferrol no MHNUSC.

Rhynchozoon quadrispinatum Zabala \& Maluquer, 1988. Especie só coñecida de Cabrera e Trafalgar. No MHNUSC hai dúas mostras de Cabrera, remitidas por M. Zabala.

Rhynchozoon rosae Souto, Reverter-Gil \& Fernández-Pulpeiro, 2010b. Especie descrita de Portugal. O seu material tipo está depositado no MNCN. No MHNUSC hai máis material da localidade tipo. Non hai máis citas da especie.

Schizomavella (Schizomavella) grandiporosa Canu \& Bassler, 1925. Especie recollida só en Alxeria, Marrocos, Portugal e Galicia. 0 material do MHNUSC, procedente de Galicia e Portugal, é o único ibérico.

Schizomavella (Schizomavella) hondti Reverter-Gil \& Fernández-Pulpeiro, 1996: Especie recollida só nas illas Británicas e Galicia. 0 material tipo está no MNHN. O material do MHNUSC, procedente de Galicia, é o único conservado en España.

Schizomavella (Schizomavella) mamillata (Hincks, 1880b). Esta especie é típicamente mediterránea pero foi atopada ocasionalmente en Portugal e en Galicia. No MHNUSC consérvase material destas dúas áreas.

Schizomavella (Schizomavella) sarniensis Hayward \& Thorpe, 1995: Especie recollida só no Canal da Mancha, Santander, Galicia e o Algarve. No MHNUSC consérvase material destas dúas últimas áreas.

Schizomavella (Schizomavella) teresae Reverter-Gil \& Fernández-Pulpeiro, 1996: Especie recollida só nas illas Británicas e Galicia. 0 material tipo está no MNHN. 0 material do MHNUSC, procedente de Galicia, é o único conservado en España.

Schizoporella cornualis Hayward \& Ryland, 1995. Na península ibérica esta especie só é coñecida de Galicia e no Algarve. 0 material conservado no MHNUSC procede destas dúas áreas e é o único ibérico.

Schizotheca divisa (Norman, 1864). Na península ibérica esta especie só foi recollida en Galicia, cuxo material consérvase no MHNUSC. É polo tanto o único material ibérico que existe.

Schizotheca tuberigera (Jullien in Jullien \& Calvet, 1903). Na península ibérica esta especie só se coñece do Golfo de Cádiz e máis de Galicia, que é de onde procede o material conservado no MHNUSC. Hai pouco material ibérico conservado. 
Sessibugula barrosoi López de la Cuadra \& García-Gómez, 1994. Especie descrita da área do Estreito de Xibraltar (o material tipo consérvase no MNCN). No MHNUSC consérvase unha colonia do Algarve. Son as dúas únicas citas da especie ata agora.

Setosella sp.: Unha colonia recollida na ría de Vigo, que seguramente corresponde a unha nova especie (véxase REVERTER-GIL et al., 2012 e Rosso et al., 2020, ambolosdous como Setosella aff. cavernicola Harmelin, 1977; e RevERTER-GIL \& SOUTO, 2021).

Smittina jordii Reverter-Gil \& Fernández-Pulpeiro, 1999. Especie descrita de Galicia e reencontrada máis tarde en Portugal. 0 material tipo está no MNHN. No MHNUSC hai dúas pequenas colonias da localidade tipo.

Smittoidea amplissima Hayward, 1979. Na península ibérica esta especie só foi recollida en Galicia, cuxo material consérvase no MHNUSC. É o único material ibérico que existe.

Spathipora comma (Soule, 1950). Na península ibérica esta especie só se coñece de Columbretes e máis de Galicia, de onde procede o material conservado no MHNUSC. Hai pouco material ibérico conservado.

Stomatoporina incurvata (Hincks, 1859). Especie moi pouco citada a nivel global. 0 material do MHNUSC, recollido en Ferrol, é o único ibérico.

Tegella unicornis (Fleming, 1828). Na península ibérica esta especie só foi citada en Galicia, cuxo material consérvase no MHNUSC. É o único material ibérico que existe.

Tricellaria inopinata d'Hondt \& Occhipinti Ambrogi, 1985. Esta especie, propia do Pacífico noroccidental, foi introducida en augas ibéricas a principios dos anos 90, e estendeuse a outras localidades atlánticas europeas. No MHNUSC consérvase material de diversas localidades ibéricas atlánticas, dende Santander ata Boca do Inferno (Portugal).

Trypostega venusta (Norman, 1864). Na península ibérica esta especie só é coñecida de Galicia e do Algarve. 0 material conservado no MHNUSC procede das dúas áreas e é o único material ibérico conservado.

Tubulipora lobifera Hastings, 1963. Na península ibérica esta especie só foi citada en Galicia. Material desta especie consérvase no MHNUSC, e é o único material ibérico que existe.

Watersipora arcuata Banta, 1969. É unha especie introducida recentemente en Europa (véxase REVERTER-GIL \& SOUTO, 2019). A primeira colonia desta especie que se encontrou en augas europeas é a conservada agora no MHNUSC, recollida en Cádiz por C.M. López-Fé. En augas ibéricas só hai dúas citas máis na costa mediterránea.

Watersipora souleorum Vieira, Spencer Jones \& Taylor, 2014. Na península ibérica esta especie só se atopou en Faro e Huelva (material conservado no MHNUSC) e en Xibraltar (material conservado no MNHN).

Watersipora subatra (Ortmann, 1890). É unha especie introducida recentemente en Europa (véxase REVERTER-GIL \& SouTo, 2019). No MHNUSC consérvanse mostras de todas as localidades ibéricas onde se citou a especie: Santander, Xixón, varios puntos de Galicia, Lisboa e o Algarve, así como material inédito recolectado no porto de Muros. 


\section{CONCLUSIÓNS}

O MHN da USC alberga catro coleccións con material de briozoos: A colección da "Estación de Bioloxía Mariña de Santander", que contén 12 mostras identificadas e citadas por BARRoso (1912); a da "Fauna Mariña de Galicia", con 10 mostras; a de Tipos con 14 mostras; e a Colección Xeral, con 1029 mostras. En total as coleccións conteñen 1065 mostras de briozoos, conservadas en seco, en alcohol ou incluso en formaldehído, correspondentes a 241 especies. Unha pequena parte está exposta ao público, mentres que a meirande parte está depositada na sala de coleccións do Museo. 0 98\% das mostras proceden de augas ibéricas, e máis en concreto o 92\% proceden de Galicia ou de Portugal. 0 84\% do material foi citado en diversas publicacións científicas e un 13\% foi ademais figurado, polo que constitúen un importante material de referencia. Unha cuarta parte das mostras teñen ademais especial relevancia por distintos motivos: As coleccións albergan catro Holotipos e dez Paratipos de seis especies; outras 59 especies son en xeral pouco frecuentes, ou ben o seu material é o único material ibérico, ou español, que se conserva.

\section{AGRADECEMENTOS}

Este traballo está dedicado a Eugenio Fernández Pulpeiro, pioneiro no estudo dos briozoos en Galicia e na península Ibérica, iniciador desta colección, e que ocupou ademais cargos de responsabilidade no MHNUSC.

Os autores queren expresar ademais o seu agradecemento a todo o persoal do MHNUSC, especialmente a Marcos González, Juanma Cutrín e Xan Guerra, pola súa amable colaboración. Tamén a todas as persoas que doaron material ás coleccións de briozoos, en especial a J.E. Trigo, H. De Blauwe, M. Zabala, J.L. Redondo e C.M. López-Fé, así como aos dous revisores anónimos.

\section{Referencias}

ADAMS, J. (1798). Description of some marine animals found on the coats of Wales by the late John Adams Esq. Transactions of the Linnean Society, 2: 7-13.

ÁlvareZ, J.A. (1991). Una revisión crítica de la obra "Briozoos de la estación de Biología marítima de Santander” publicada por Manuel Jerónimo Barroso en 1912. Miscel-lània Zoològica, 15: 185-193.

ÁLVAREZ, J.A. (1992). Fenestrulina asturiasensis sp. nov. (Bryozoa: Cheilostomida) from the northern coast of the Iberian Peninsula. Journal of the Marine Biological Association of UK, 72: 727-730. http://dx.doi.org/10.1017/S002531540005949X

Álvarez, J.A. (1993). Fenestrulina barrosoi sp. nov. (Bryozoa: Cheilostomida) with a review of the genus Fenestrulina on the Iberian Peninsula. Journal of the Marine Biological Association of UK, 73: 831835. http://dx.doi.org/10.1017/S0025315400034755

Appeltans, W., Ahyong, S.T., ANDerson, G., Angel, M.V., ARtois, T., Bailly, N., BAmber, R., Barber, A., Bartsch, I., Berta, A., BŁażewicz- Paszkowycz, M., Bock, P., Boxshall, G., BoyKo, C.B., Brandão, S.N., Bray, R.A., Bruce, N.L., Cairns, S.D., Chan, T.Y., Chan, L., Collins, A.G., Cribb, T., Curini-Galletti, M., DahdouhGuebas, F., Davie, P.J.F., DaWson, M.N., De Clerck, O., Decock, W., De Grave, S., DE Voogd, N.J., Domning, D.P., Emig, C.C., Erséus, C., Eschmeyer, W., Fauchald, K., Fautin, D.G., Feist, S.W., Fransen, C.H.J.M., FuruYa, H., Garcia-Alvarez, O., Gerken, S., Gibson, D., GitTenberger, A., Gofas, S., Gómez-Daglio, L., Gordon, D.P., GuirY, M.D., Hernandez, F., HoEKSEMA, B.W., Hopcroft, R., JAUME, D., KirK, P., KoedAM, N., 
Koenemann, S., Kolb, J.B., Kristensen, R.M., Kroh, A., Lambert, G., Lazarus, D.B., Lemaitre, R., LONGShaW, M., LOWRY, J., MACPHERSON, E., MAdiN, L.P., MAH, C., MAPSTONE, G., MCLAUGHLin, P., MEES, J., Meland, K.L., Messing, C.G., Mills, C.E., Molodtsova, T.N., Mooi, R., Neuhaus, B., NG, P.K.L., Nielsen, C., Norenburg, J., Opresko, D.M., Osawa, M., Paulay, G., Perrin, W., Pilger, J.F., Poore, G.C.B., Pugh, P., Read, G.B., Reimer, J.D., Rius, M., Rocha, R.M., RosenberG, G., Saiz-Salinas, J.I.; Scarabino, V., Schierwater, B., Schmidt-Rhaesa, A., Schnabel, K.E., Schotte, M., Schuchert, P., Schwabe, E., Segers, H., Self-Sullivan, C., Shenkar, N., Siegel, V., Sterrer, W., Stöhr, S., Swalla, B., Tasker, M.L., Thuesen, E.V., Timm, T., Todaro, A., Turon, X., Tyler, S., Uetz, P., VAN DER LAND, J., VANHOORne, B., VAN OfWEgen, L.P., Van Soest, R.W.M., VAnaverbeKe, J., Walker-Smith, G., Walter, T.C., Warren, A., Williams, G., WiLSON, S.P. \& COSTELlo, M.J. (2012). The magnitude of global marine species diversity. Current Biology, 22, 1-14. http://dx.doi.org/10.1016/i.cub.2012.09.036

Audouin, J.V. (1826). Explication sommaire des planches de polypes de l'Egypte et de la Syrie, publiées par Jules-César Savigny. In Audouin J.V. (ed.) Description de l'Egypte, ou recueil des observations et des recherches qui ont était faites en Egypte pendant l'expédition de l'armée française. Histoire Naturelle Tome 1, 4 partie. Imprimerie Impériale, Paris. 339 pp.

BANTA, W.C. (1969). Watersipora arcuata, a new species in the subovoidea - cucullata - nigra complex (Bryozoa, Cheilostomata). Bulletin of the Southern California Academy of Science, 68: 96-102.

Barroso, M.G. (1912). Briozoos de la Estación de Biología Marítima de Santander. Trabajos del Museo de Ciencias Naturales, 5: 1-64.

BArroso, M.G. (1919). Notas sobre briozoos españoles. Boletín de la Real Sociedad española de Historia Natural (Sección Biológica), 19: 340-347.

BERNING, B. \& KUKLIŃSKI, P. (2008). North-east Atlantic and Mediterranean species of the genus Buffonellaria (Bryozoa, Cheilostomata): implications for biodiversity and biogeography. Zoological Journal of the Linnean Society, 152: 537-566. http://dx.doi.org/10.1111/j.1096-3642.2007.00379.x

Bishop, J.D.D. \& HousehAM, B.C. (1987). Puellina (Bryozoa; Cheilostomatida; Cribrilinidae) from British and adjacent waters. Bulletin of the British Museum of Natural History, Zoology, 53: 1-63.

BOE (2020). Resolución de 3 de diciembre de 2020, de la Secretaria de Estado de Medio Ambiente, por la que se revisa y amplía la lista patrón de las especies silvestres presentes en España. Boletin Oficial del Estado, A-2020-16499.

Bugallo Rodríguez, Á. (2003). O Museo de Historia Natural da Universidade de Santiago de Compostela. Santiago de Compostela, Parlamento de Galicia, Universidade de Santiago de Compostela, Servicio de Publicacións e Intercambio Científico. 365 pp.

BuSK, G. (1856). Zoophytology. Quarterly Journal of Microscopical Science, 4: 308-312. http://biodiversitylibrary.org/page/27676524

CANu, F. \& BASSleR, R.S. (1925). Les Bryozoaires du Maroc et de Mauritanie. Mémoires de la Société des Sciences naturelles du Maroc, 10: 1-79.

CÉSAR-Aldariz, J., FernándeZ-PulPeiro, E. \& ReVErTER-Gil, O. (1999). A new species of the genus Celleporella (Bryozoa: Cheilostomatida) from the European Atlantic coast. Journal of the Marine Biological Association of the United Kingdom, 79(1): 51-55. http://dx.doi.org/10.1017/S0025315498000058

Couch, R.Q. (1844). A Cornish fauna: being a compendium of the natural history of the country, intended to form a companion to the collection in the Royal Institution of Cornwall... part 3. The zoophytes and calcareous corallines. Royal Institution of Cornwall, Truro. https://doi.org/10.5962/bhl.title.87783

ElLIS, J. \& Solander, D.C. (1786). The Natural History of Many Curious and Uncommon Zoophytes, collected from various parts of the globe. White \& Elmsly, London. 206 pp. https://doi.org/10.5962/bhl.title.2145

FABRICIUS, O. (1780). Fauna Groenlandica, systematices sistems animalia Groenlandiae occidentalis hactenus indagata. I.G. Rothe, Hafniae; Lipsiae. 452 pp. https://doi.org/10.5962/bhl.title.61754

FERnÁndEZ PulPEIRO, E. \& REVERTER GIL, O. (1993). Le genre Ellisina (Bryozoa, Cheilostomida) dans les côtes européennes. Description d'Ellisina gautieri sp. nov. Cahiers de Biologie Marine, 34(1): 93-101. 
FLEMING, J. (1828). A history of British animals, exhibiting their descriptive characters and systematic arrangement of the genera and species of quadrupeds, birds, reptiles, fishes, Mollusca, and Radiata of the United Kingdom. Bell \& Bradfute, Edinburgh. 565 pp. https://doi.org/10.5962/bhl.title.12859

Gordon, D.P., BOCK, P.E., SOUTO-DERUnGS, J. \& REVERTER GIL, O. (2019). A bryozoan tale of two continents: faunistic data for the Recent Bryozoa of Greater Australia (Sahul) and Zealandia, with European comparisons. In: Schmidt, R., Reid, C.M., Gordon, D.P., Walker-Smith, G. \& Percival, I.P. (Eds.), Bryozoan Studies 2016. Proceedings of the Seventeenth International Bryozoology Conference. 10-15 April, 2016, Melbourne, Australia: 13-22. Australasian Palaeontologists, Sydney.

GoRdon, D.P., TAYLOR, P.D. \& BigEY, F.P. (2009). Phylum Bryozoa. Moss animals, sea mats, lace corals. In: Gordon, D.P. (Ed.), New Zealand Inventory of Biodiversity. Volume I. Animalia, Radiata, Lophotrochozoa, Deuterostomia: 271-297. Canterbury University Press, Canterbury.

HARMELIN, J.-G. (1977). Bryozoaires du banc de la Conception (Nord des Canaries). Campagne Cineca I de 'Jean Charcot'. Bulletin du Muséum national d'Histoire naturelle, Série 3, 492: 1057-1076.

Harmelin, J.-G., Bishop, J.D.D., Madurell, T., Souto, J., SPEnCER JoneS, M.E. \& Zabala, M. (2019). Unexpected diversity of the genus Collarina Jullien, 1886 (Bryozoa, Cheilostomatida) in the NE AtlanticMediterranean region: new species and reappraisal of $C$. balzaci (Audouin, 1826) and C. fayalensis Harmelin, 1978. Zoosystema, 41 (21): 385-418. https://doi.org/10.5252/zoosystema2019v41a21

Harmelin, J.-G., Ostrovsky, A.N., CÁCERES-Chamizo, J. \& SANnER, J.A. (2011). Bryodiversity in the tropics: taxonomy of Microporella species (Bryozoa, Cheilostomata) with personate maternal zooids from Indian Ocean, Red Sea and southeast Mediterranean. Zootaxa, 2798: 1-30. http://www.mapress.com/zootaxa/list/2011/2798.html

HaSSALL, A.H. (1841). Supplement to a catalogue of Irish Zoophytes. Annals and Magazine of Natural History, 7: 363-373. https://doi.org/10.1080/03745484109442710

HASSALL, A.H. (1842). Remarks on the genus Lepralia of Dr. Johnston with descriptions of six undescribed species. Annals and Magazine of Natural History, 9: 407-414. https://doi.org/10.1080/03745484209445355

HAstings, A.B. (1963). Notes on Polyzoa (Bryozoa). 5. Some Cyclostomata collected by R.C. Osburn in 1933 and 1953. Annals and Magazine of Natural History, (13)6: 113-127.

HAYWARD, P.J. (1979). Systematic notes on some British Ascophora (Bryozoa, Cheilostomata). Zoological Journal of the Linnean Society, 66 (1): 73-90.

HAYWARD, P.J. \& RYLAND, J.S. (1995). The British species of Schizoporella (Bryozoa, Cheilostomatida). Journal of Zoology, London, 237: 37-47.

HAYWARD, P.J. \& THORPE, J.P. (1995). Some British species of Schizomavella (Bryozoa: Cheilostomata). Journal of Zoology, London, 235: 661-676.

HINCKS, T. (1851). Notes on British zoophytes, with descriptions of some new species. Annals and Magazine of Natural History, (2)8: 353-362.

HINCKS, T. (1859). Additional list of Polyzoa. Rep Belfast dredging Committee 1858: 293.

HiNCKS, T. (1862). Catalogue of the Zoophytes of South Devon and Cornwall. Annals and Magazine of Natural History, (3)9: 200-207. http://biodiversitylibrary.org/page/22219654

HINCKS, T. (1877). On British Polyzoa. Part I. Annals and Magazine of Natural History, (4)20: 212-218.

HinCKS, T. (1880a). Contributions towards a general history of the marine Polyzoa. Part II. Foreign Membraniporina. Annals and Magazine of Natural History, (5)6: 81-92.

HINCKS, T. (1880b). A History of the British marine Polyzoa. Van Voorst, London. 601 pp.

HINCKS, T. (1887). The Polyzoa of the Adriatic, II. Annals and Magazine of Natural History, (5)19: 302-316. https://doi.org/10.1080/00222938709460247

HondT, J.-L. D' (1970). Campagne d'essais du Jean Charcot (3-8 decembre 1968). 5. Bryozoaires. Bulletin du Muséum National d'Histoire Naturelle (2e Ser), 42: 232-256. 
HondT, J.-L. D' \& OCChIPINTI AmBroGI, A. (1985). Tricellaria inopinata, n.sp., un nouveau Bryozoaire Cheilostome de la faune Méditerrannée. Pubblicazioni della Stazione Zoologica di Napoli Marine Ecology), 6: 35-46.

Jebram, D. (1985). Panolicella nutans gen. et sp.n. (Bryozoa, Ctenostomata), its description, development and laboratory culture. Zoologica Scripta, 14 (1): 11-18. http://dx.doi.org/10.1111/j.1463409.1985.tb00174.x

Johnston, G. (1832). A descriptive catalogue of the Recent zoophytes found on the coast of North Durham. Transactions of the Natural History Society of Northumberland, Durham and Newcastle-upon-Tyne, 2: 239-272.

Johnston, G. (1847). A History of the British Zoophytes. Van Voorst, London. 499 pp. https://doi.org/10.5962/bhl.title.19627

JulliEN, J. (1882). Dragages du «Travailleur», Bryozoaires. Espèces draguées dans l'Océan Atlantique en 1881. Espèces nouvelles ou incomplètement décrites. Extrait du Bulletin de la Société zoologique de France 7: 1-33. http://dx.doi.org/10.5962/bhl.title.4721

Jullien, J. \& CAlvet, L. (1903). Bryozoaires provenant des Campagnes de «l'Hirondelle» (1886-1888). Résultats des Campagnes Scientifiques accomplies sur son yacht, par Albert I, 23: 1-188.

KING, W. (1846). An account of some shells and other invertebrate forms found on the coasts of Northumberland and Durham. Annals and Magazine of Natural History, 18: 233-251. https://doi.org/10.1080/037454809494420

KUKLIŃSKI, P. \& TAYLOR, P.D. (2008). Arctic species of the cheilostome bryozoan Microporella, with a redescription of the type species. Journal of Natural History, 42 (27-28), 1893-1906. http://dx.doi.org/10.1080/00222930802126904

LAMARCK, J.B. (1816). Histoire naturelle des Animaux sans Vertèbres ... précédée d'une introduction offrant la détermination des caractéres essentiels de l'animal, sa distinction du végétal et des autres coorps naturels, enfin, exposition des principes fondamentaux de la zoologie. Verdiere, Paris. 568 pp.

LEVINSEN, G.M.R. (1909). Morphological and systematic studies on the cheilostomatous Bryozoa. Nationale Forfatterers Forlag, Copenhagen. 431 pp. https://doi.org/10.5962/bhl.title.5690

LINNAEUS, C. (1753). Species plantarum... Holmiæ:Impensis Laurentii Salvii. 560 pp.

LINNAEUS, C. (1758). Systemae naturae per regna tria naturae, secundum classes, ordines, genera, species, cum characteribus, differetiis, synonymis, locis Ed.10. Laurentii Salvii, Holmiae. 824 pp.

LiNNAEUS, C. (1767). Systemae naturae per regna tria naturae, secundum classes, ordines, genera, species, cum characteribus, differetiis, synonymis, locis Regnum Animale. Laurentii Salvii, Holmiae.

LóPEZ DE LA CuAdRA, C.M. \& GARCíA-GóMEZ, J.C. (1994). Bryozoa Cheilostomata: the genus Amphiblestrum in the Western Mediterranean and the first Sessibugula of Atlantic waters. Journal of Natural History, 28(3): 683-693. http://dx.doi.org/10.1080/00222939400770311

MANZONI, A. (1870). Bryozoi fossili italiani. Quarta contribuzione. Sitzungsberichte der kaiserlichen Akademie der Wissenschaften in Wien (Abt 1), 61, 323-349.

Neviani, A. (1896). Briozoi postpliocenici di Spilinga (Calabria). Atti Accademia Gioenia di Scienze Naturali in Catania ser. 4, v.9, memoria IX: 1-66.

Norman, A.M. (1864). On undescribed British Hydrozoa, Actinozoa and Polyzoa. Annals and Magazine of Natural History, 13(3): 82-90. https://doi.org/10.1080/00222936408681578

OKADA, Y.\& MAWATARI, S. (1937). On the collection of Bryozoa along the coast of Onagawa Bay and its vicinity, the northern part of Honshu, Japan. Science Reports Tôhoku University, 11: 433-445.

ORTMAnN, A. (1890). Die Japanische Bryozoenfauna. Bericht über die von Herrn Dr. L. Döderlein im Jahre 1880-81 gemachten Sammlungen. Archiv für Naturgeschichte, 54: 1-74.

PALLAS, P.S. (1766). Elenchus zoophytorum sistens generum adumbrationes generaliores et speciarum cognitarum succintas descriptiones cum selectis auctorus synonymis. Petrum van Cleef, HagaeComitum. 451 pp. https://doi.org/10.5962/bhl.title.6595 
Prouno, H. (1892). Contribution à l'histoire des Bryozoaires. Archives de Zoologie expérimentale et Génerale, 2: 557-656.

RAMALHO, L.V., LóPEZ-FÉ, C.M., MATEO-RAmíREZ, Á. \& RUEDA, J.L. (2020). Bryozoa from deep-sea habitats of the northern Gulf of Cádiz (Northeastern Atlantic). Zootaxa, 4768 (4): 451-478. https://doi.org/10.11646/zootaxa.4768.4.1

REuSS, A.E. (1848). Die fossilen Polyparien des Wiener Tertiärbeckens. Haidingers Naturwissenschaftlichen Abhandlungen, 2: 1-109.

REVERTER-Gil, O. \& FERnÁNDEZ-PulPEIRo, E. (1996). Some species of Schizomavella (Bryozoa, Cheilostomatida) from the Atlanto-Mediterranean region. Cahiers de Biologie Marine, [1995], 36(4): 259-275.

REVERTER-GiL, O. \& FERnÁndEZ-PulPEIRo, E. (1999). Some records of Bryozoans from NW Spain. Cahiers de Biologie Marine, 40(1): 35-45.

REVERTER-Gil, O. \& FERnÁndEZ-PulPEIRO, E. (2007). A new name for Puellina parva Reverter \& Fernández, 1996 (Bryozoa, Cheilostomatida). Journal of Natural History, 41(9-12): 729-730. http://dx.doi.org/10.1080/00222930701261810

REVERTER-GIL, O. \& SoUTO, J. (2017). Filo Bryozoa. In: (Ed.). Inventario de la biodiversidad marina de Galicia: Proyecto LEMGAL. Conselleria do Mar, Xunta de Galicia, Santiago de Compostela, 237-251.

REVERTER-GIL, O. \& SouTo, J. (2019). Watersiporidae (Bryozoa) in Iberian waters: an update on alien and native species. Marine Biodiversity, 49(6): 2735-2752. https://doi.org/10.1007/s12526-019$\underline{01003-4}$

ReVErter-Gil, O. \& Souto, J. (2021). Two new species of cheilostomate Bryozoa from Iberian waters. European Journal of Taxonomy, 760: 16-31. https://doi.org/10.5852/ejt.2021.760.1437

Reverter-Gil, O., Souto, J. \& FernándeZ-PulPeiro, E. (2009). Three new species of Iberian cheilostomate Bryozoa. Journal of the Marine Biological Association of the United Kingdom, 89 (7), 1499-1506. https://doi.org/doi:10.1017/S0025315409000496

Reverter-Gil, O., Souto, J. \& FernándeZ-PulPeiro, E. (2012). New and little known species of Bryozoa from Iberian Atlantic waters. Zoosystema, 34 (1): 157-170. https://doi.org/10.5252/z2012n1a7

REVERTER-Gil, O., Souto, J. \& FERnÁnDEZ-PulPEIRo, E. (2014). Annotated checklist of Recent marine Bryozoa from continental Portugal. Nova Acta Científica Compostelana (Bioloxía), 21: 1-55. http://www.usc.es/revistas/index.php/nacc/issue/view/208

Reverter-Gil, O., Souto, J. \& Fernández-PulPeiro, E. (2016). Bryozoa I. Ctenostomata. In: Ramos, M.A. et al. (Eds.), Fauna Ibérica, vol. 43. Museo Nacional de Ciencias Naturales. CSIC. Madrid. 308 pp.

REVERTER-GiL, O., SouTo, J. \& TRIGo, J.E. (2019). New species and new records of bryozoans from Galicia (NW $\begin{array}{llllll}\text { Spain). Journal of } & \text { Natural }\end{array}$ https://doi.org/10.1080/00222933.2019.1582815

Rosso, A., Di MARTino, E. \& Gerovasileiou, V. (2020). Revision of the genus Setosella (Bryozoa: Cheilostomata) with description of new species from deep-waters and submarine caves of the Mediterranean Sea. Zootaxa, 4728 (4): 401-442. https://doi.org/10.11646/zootaxa.4728.4.1

SÁnchez Ron, J.M. (2020). El país de los sueños perdidos. Historia de la ciencia en España. Taurus, Barcelona, 1150 pp.

SiLÉN, L. \& HARMELIN, J.G. (1976). Haplopoma sciaphilum sp. n., a cave-living bryozoan from the Skagerrak and the Mediterranean. Zoologica Scripta, 5: 61-66. https://doi.org/10.1111/j.14636409.1976.tb00682.x

Soule, J.D. (1950). A new species of Terebripora from the Pacific (Bryozoa Ctenostomata). Journal of the Washington Academy of Sciences, 40(11): 378-381.

Souto, J., NASCimento, K.B., ReVERTER-Gil, O. \& Vieira, L.M. (2018). Dismantling the Beania magellanica (Busk, 1852) species complex (Bryozoa, Cheilostomata): two new species from European waters. Marine Biodiversity, 49: 1505-1518. https://doi.org/10.1007/s12526-018-0925-2 
Souto, J., REVERTER-Gil, O. \& FernándeZ-PulPeiro, E. (2010a). Bryozoa from detritic bottoms in the Menorca Channel (Balearics, Western Mediterranean), with notes on genus Cribellopora. Zootaxa, 2536: 3652.

Souto, J., REVERTER-Gil, O. \& FERnández-PulPEIRo, E. (2010b). Gymnolaemate bryozoans from the Algarve (southern Portugal): new species and biogeographical considerations. Journal of the Marine Biological Association of the United Kingdom, 90 (7), 1417-1439. https://doi.org.org/10.1017/S0025315409991640

Sowerby, J. (1805). The British Miscellany. No. 8. Part 1. Printed by R. Taylor \& Co., London, 131 pp.

VAN BENEDEN, P.J. (1845). Récherches sur l'anatomie, la physiologie et le développement des Bryozoaires qui habitent la côte d'Ostende. Nouvelle Memoires de l'Academie royale des sciences, des lettres et des beaux-arts de Belgique, 18: 1-44.

VIEIRA, L.M. \& SPENCER JONES, M.E. (2012). The identity of Sertularia reptans Linnaeus, 1758 (Bryozoa, Candidae). Zootaxa, 3563: 26-42. http://www.mapress.com/zootaxa/list/2012/3563.html

VIEIRA, L.M., SPENCER JONES, M.E. \& TAYLOR, P.D. (2014). The identity of the invasive fouling bryozoan Watersipora subtorquata (d'Orbigny) and some other congeneric species. Zootaxa, 3857 (2): 151182. https://doi.org.org/10.11646/zootaxa.3857.2.1

VIEIRA, L.M., SPENCER JONES, M.E. \& WinSTON, J.E. (2013). Cradoscrupocellaria, a new bryozoan genus for Scrupocellaria bertholletii (Audouin) and related species (Cheilostomata, Candidae): taxonomy, $\begin{array}{llllll}\text { biodiversity and distribution. } & \text { Zootaxa, } & 3707 & \text { (1): } & \text { 1-63. }\end{array}$ http://www.mapress.com/zootaxa/list/2013/3707(1).html

Waters, A.W. (1879). On the Bryozoa (Polyzoa) of the Bay of Naples. Annals and Magazine of Natural History (series 5) 3: 114-126, 192-202. https://doi.org/10.1080/00222937908682488

ZABALA, M., \& MALUQUER, P. (1988). Illustrated keys for the classification of Mediterranean Bryozoa. Treballs del Museu de Zoologia, Barcelona, $4:$ 1-294. http://www.raco.cat/index.php/TreballsMZ/article/view/108369/168548 